\title{
GRADUAÇÃO EM HISTÓRIA NO EXTREMO NORTE DO BRASIL: DESAFIOS E POSSIBILIDADES
}

\section{UNDERGRADUATE COURSE IN HISTORY IN THE FAR NORTH BRAZIL: CHALLENGES AND POSSIBILITIES}

\author{
José Petrúcio Farias Júnior ${ }^{1}$ \\ Ana Cristina Rocha Silva²
}

\begin{abstract}
RESUMO: O presente artigo pretende abordar as experiências iniciais do processo de expansão da Universidade Federal do Amapá (UNIFAP) no município de Oiapoque, extremo norte do país, no que diz respeito à implantação do curso de graduação em História. Por se tratar de um curso de graduação voltado à formação de professores, nossas reflexões serão norteadas pelos seguintes questionamentos: o que significa ser professor de história no extremo norte do país? que práticas de ensino de História no ensino superior podem promover uma ação educativa para o ser humano que se constitui numa circunstância de pobreza e marginalização? A fim de fundamentar as reflexões propostas, o texto foi construído de forma a apresentar a trajetória histórica do município de Oiapoque/AP; destacar os atuais desafios para o desenvolvimento qualitativo do lugar; e indicar, a partir da realidade social do município, que tipo de ensino de História perseguimos.
\end{abstract}

Palavras-chave: Prática de ensino de História. Ensino superior. Graduação em História

\begin{abstract}
This article intend to deal with the early experiences of the expansion process of the Universidade Federal do Amapá (UNIFAP) in the municipality of Oiapoque, extreme north of the country, with regard to the implementation of the undergraduate course in History. Because it is an undergraduate course focus on training teachers, our thoughts will be guided by the following questions: what mean being a professor of history at the north of the country? Which history teaching practices in higher education can promote an educational activity for the human being who is in a condition of poverty and marginalization? In order to support the given reflections, the text was constructed in order to present the historical trajectory of the city of Oiapoque / AP; highlight the current challenges for the qualitative development of the place; and indicate, from the social reality of the city, what kind of history teaching we pursue.
\end{abstract}

Keywords: Teaching practice. Higher education. Graduate in History.

\footnotetext{
${ }^{1}$ Doutor em História pela UNESP/Franca. Professor da Universidade Federal do Amapá (UNIFAP)

2 Mestre em Direito Ambiental e Políticas Públicas pela Universidade Federal do Amapá (UNIFAP)
} 


\section{Introdução}

\section{Trajetória história}

Distante da capital (Macapá) cerca de 600 quilômetros, o município de Oiapoque situa-se no extremo norte do estado do Amapá, na fronteira entre Brasil e Guiana Francesa. O acesso se dá por uma única via, a BR-156. Tal rodovia corta o estado de sul a norte e, apesar de ter sua construção iniciada na década de 1940, até hoje não teve sua pavimentação concluída.

Como exposto na Figura 1, no trecho que segue até Oiapoque, aproximadamente 120 quilômetros da BR-156 estão por ser asfaltados. Assim, no período do inverno Amazônico (dezembro a junho), muitos atoleiros se formam ao longo da via, dificultando (e muitas vezes impedindo) o acesso ao município.

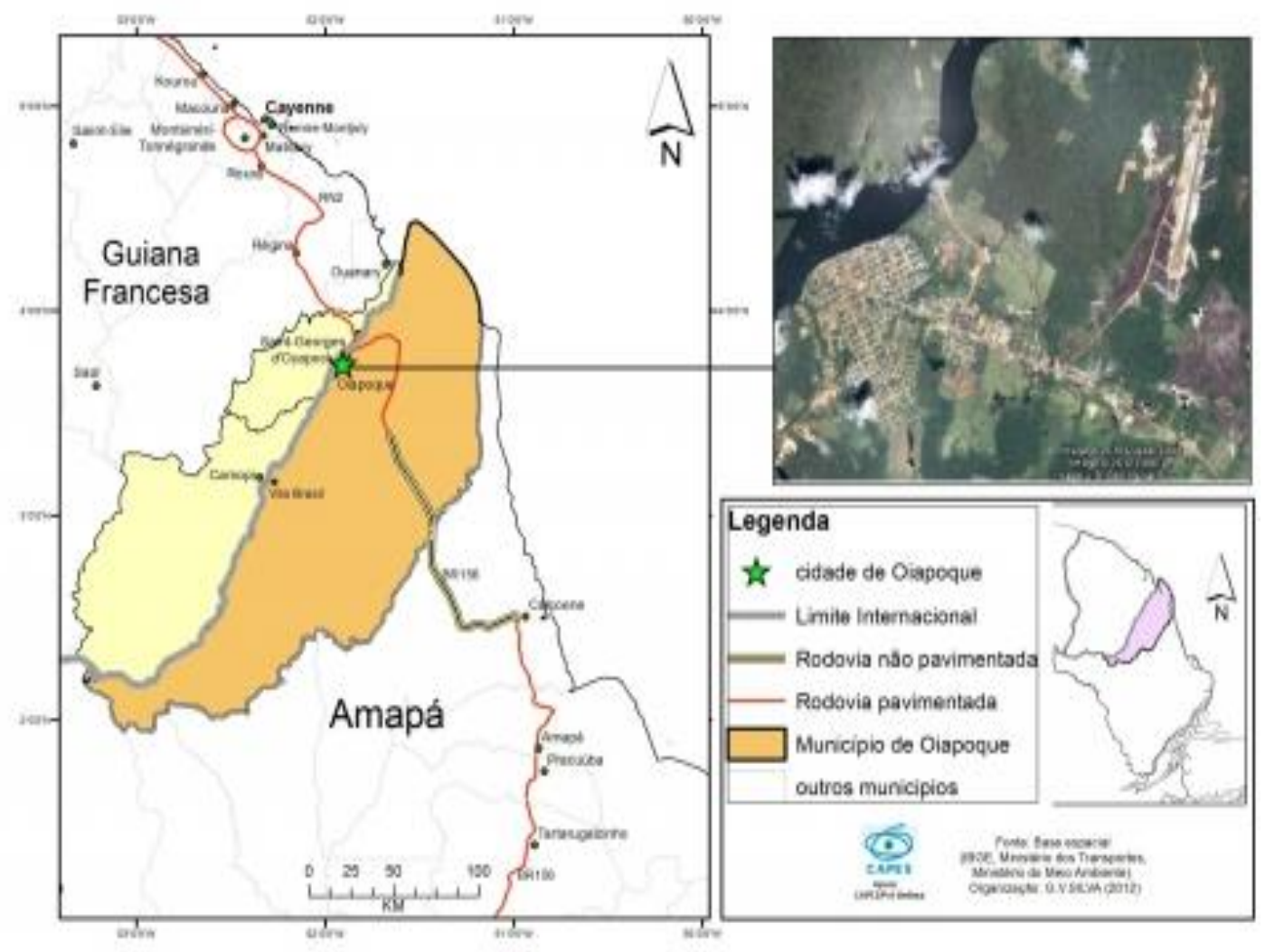

Figura 1: Localização de Oiapoque-AP. Fonte: Silva (2013)

Marcado por conflitos que conectam passado e presente, o atual território do município de Oiapoque é objeto de disputas desde o século XVI. Como exporemos nos parágrafos à frente, a história do lugar confunde-se com a própria história da dominação e expansão portuguesa na Amazônia. 
A partir dos desdobramentos da expansão ultramarina (século XV), muitos portugueses, espanhóis, franceses, ingleses e holandeses tiveram seus primeiros contatos com a floresta Amazônica através do rio Oiapoque. Em decorrência dos limites estabelecidos pelo Tratado de Tordesilhas, a região que compreende os rios Orinoco e Amazonas (na qual Oiapoque se inclui) estava sob o domínio espanhol. Porém, ao dar prioridade à exploração das riquezas do México e Peru, os espanhóis desprezaram essa região, cujo litoral era inóspito (GRANGER, 2012).

Excluídos do Tratado de Tordesilhas, França, Inglaterra e países baixos, aproveitaram o desinteresse espanhol e se apoderaram de parte dessa porção de terras em fins do século XVII. Nesse contexto, deu-se a criação das Guianas britânica, holandesa e francesa. Conforme Granger (2012), os franceses possuíam grande interesse nesse território devido à abundância de riquezas naturais. A junção dos interesses na exploração de recursos naturais com a imprecisão nos mapas dos limites entre as colônias francesa e portuguesa acirraram os conflitos pelo domínio de parte da outrora denominada Capitania do Cabo Norte.

Para o autor em destaque, a França entendia que sua soberania se estendia entre os rios Orinoco e Amazonas, compreendendo a totalidade das Guianas litorais. Por sua vez, os portugueses haviam recebido da Coroa espanhola a Capitania do Cabo Norte até o rio Oiapoque (limite com o povoamento francês).

Ao indicar um rio denominado "Japoc ou Vicente Pinção" como fronteira para as colônias em disputa, o Tratado de Ultrech (1713) é um dos primeiros documentos utilizados para tentar neutralizar os conflitos. Por não possuir localização precisa nos mapas, os portugueses acreditavam que esse rio era o Oiapoque. Já os franceses defendiam que tal rio correspondia a outros localizados mais perto do cobiçado Amazonas. Primeiramente, diziam que era o Cassiporé, em seguida, o Calçoene e, por último, disseram ser o rio Araguari (GRANGER, 2012).

Em 1797, as guerras revolucionárias e napoleônicas permitiram aos franceses impor aos portugueses a fronteira no rio Calçoene, através do tratado de Paris. Em 1801, o tratado de Badajós avançou o limite para o rio Araguari. Porém, percebendo a fragilidade da colônia francesa, o regente de Portugal, Dom João, invadiu a Guiana Francesa para, dentre outras coisas, fixar a fronteira no rio Oiapoque. Conquistada pelos portugueses em 1809, a Guiana Francesa não teve seu território anexado ao Brasil. A queda de Napoleão, em 1815, permitiu a 
restituição da Guiana à França, em 1817, via o tratado de Paris, que definia com dados geográficos precisos a fronteira no rio Oiapoque, como vislumbravam os portugueses (GRANGER, 2012).

Após toda essa trajetória, o impasse entre França e Portugal parecia estar resolvido. No entanto, recuperar a Guiana sem o acesso ao rio Amazonas não era interessante para os franceses. Assim, aproveitando-se dos tumultos surgidos com a independência do Brasil em 1822, a França persiste em tentar estender seus domínios territoriais até o rio Araguari (GRANGER, 2012). Nesse contexto surge o território do "Contestado franco-brasileiro", exposto na Figura 2.

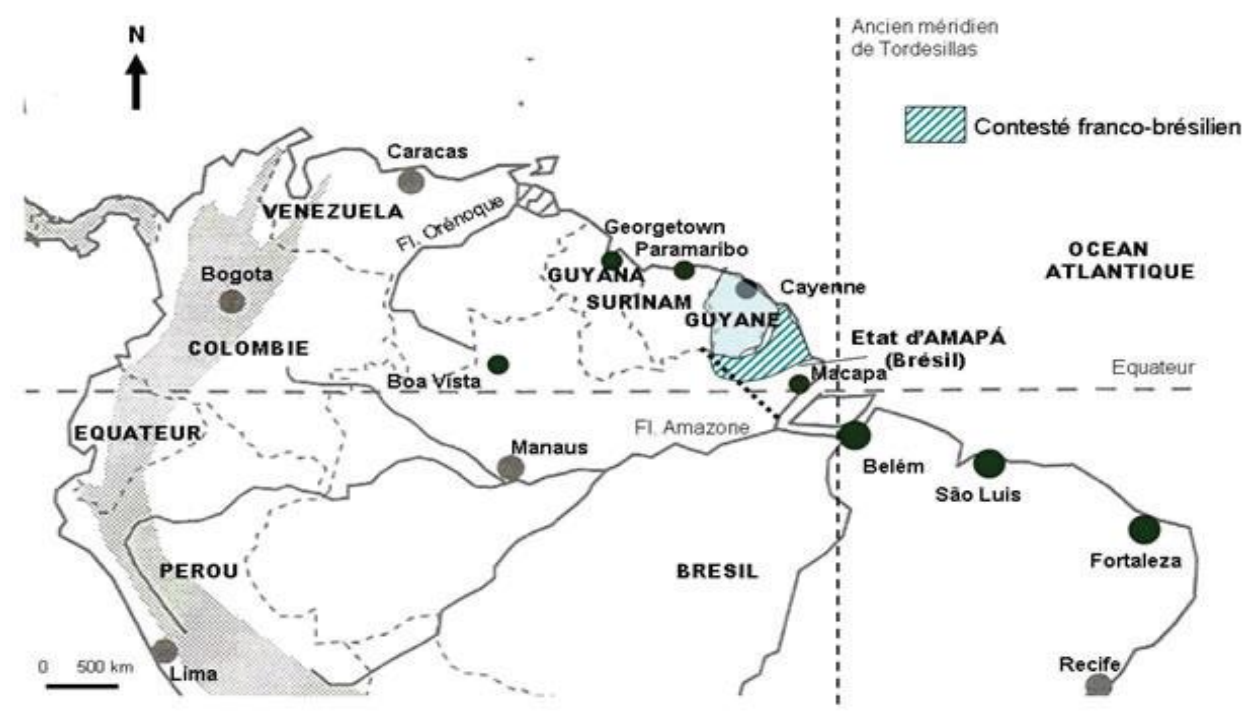

Figura 2: Mapa de localização da área contestada por França e Brasil. Fonte: Granger, 2012, p. 37.

De 1841 a 1900, a área do Contestado franco-brasileiro foi neutralizada e deixou de pertencer tanto à França quanto ao Brasil. Na tentativa de ajudar a França a conquistar a área em litígio, a partir de 1880, exploradores como Condreau e Brosseau adentraram a região neutralizada a fim de favorecer uma colonização de povoamento que, naquele momento, era oficialmente proibida pelo acordo de neutralização assinado entre os dois países (GRANGER, 2012).

Nessa empreitada, Condreau agiu no sentido de conquistar a independência da república de "Guyane indépendante" em Cunani, aldeia próxima ao atual município de Calçoene. Ao sentir que o Brasil estava em posição favorável a futuras negociações, a França optou por não causar mal-estar com o Brasil naquele 
momento e declinou no apoiou para Condreau. Apesar disso, a república de Cunani, mesmo com apenas um ano de existência, foi capaz de emitir selos e moedas e ainda articular apoios diplomáticos com outros países (GRANGER, 2012).

Em 1894, a descoberta de jazidas de ouro na região de Calçoene efervesceu o conflito entres os dois países. A área do Contestado permaneceu em litígio até $1^{0}$ de maio de 1900, quando, então, a região foi definitivamente concedida ao Brasil, através da intermediação da Comissão de Arbitragem de Genebra que a adicionou como parte do estado do Pará, com o nome de Araguaí.

A palavra Oiapoque tem suas origens no tupi-guarany. É uma derivação do termo "oiap-oca", que significa "casa dos Wajãpi". Os primeiros indícios de povoamento não indígena do espaço onde se localiza a cidade de Oiapoque na atualidade remontam ao século XIX. Ao adentrarem a área habitada pelos Wajãpi, antilhanos e crioulos guianenses ocuparam paulatinamente o local, forçando a migração desses nativos para a Serra do Tumucumaque (PENNAFORT, 1984).

Martinica do Oiapoque foi o primeiro nome atribuído ao local. Na segunda metade da década de 1920, vislumbrando retirar a conotação francesa, Marechal Cândido Rondon sugeriu a modificação do nome e, a partir de então, o local passou de denominar-se Vila do Espírito Santo. O nome atual veio em 1945 quando a pequena Vila tornou-se cidade sede do recém-criado município de Oiapoque.

\section{Aspectos contemporâneos}

Nos dias atuais, o município é composto pela sede (Oiapoque) e por dois distritos, Clevelândia do Norte (área militar do exército brasileiro) e Vila Velha (propriedade de agroextrativistas). Segundo o censo do IBGE (2010), Oiapoque possui aproximadamente 20.426 habitantes. Desse total, 13.873 concentra-se na zona urbana e 6.553 estão na zona rural.

A população indígena que habita os limites territoriais de Oiapoque está estimada em 7.000 indivíduos. A maior parte desse quantitativo de indígenas se distribui em 35 aldeias e outra parte menor vive na área urbana do município. Juntos, eles formam quatro povos (os Palikur, os Galibi-Kali 'na, os Karipuna e os Galibi-Marworno) e ocupam três Terras Indígenas contíguas (TI Uaçá, TI Juminã e 
TI Galibi do Oiapoque). Essas terras são todas homologadas e abrangem 23\% da extensão territorial de Oiapoque (VIDAL, 2007).

De acordo com Silva (2013), a economia local está assentada na pesca e na agricultura. No entanto, a potencialização e desenvolvimento dessas atividades são impedidas pela falta de titularidade das terras e a consequente impossibilidade de financiamento junto a instituições bancárias e agências de fomento. Essa dificuldade está relacionada ao contexto ambiental do município.

Ao integrar um estado que possui $72 \%$ de seu território destinado a áreas ambientais protegidas, os municípios do extremo norte do Amapá (Calçoene e Oiapoque) possuem $52 \%$ de sua área total protegida por Unidades de Proteção Integral (Parque Nacional Montanha do Tumucumaque e Cabo Orange); outros 30\% protegidos por Unidades de Conservação Sustentável e 14\% homologados como Terras Indígenas. Assim, conforme ilustrado na Figura 3, o território do extremo norte amapaense possui apenas $3,74 \%$ de sua área livre para a ocupação de centros urbanos e terras agrícolas.

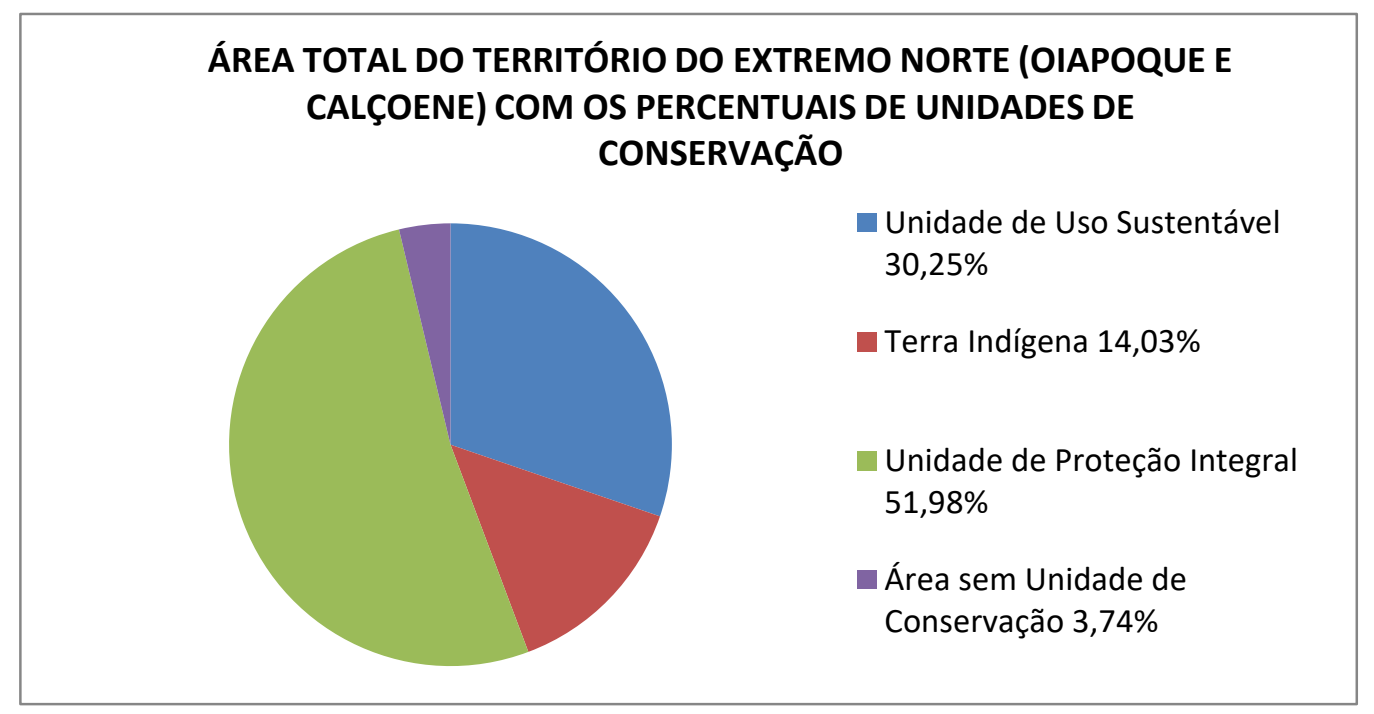

Figura 3: Percentual de Unidades de Conservação no Extremo Norte. Fonte: INCRA (2011).

Segundo o INCRA (2011), o alto percentual de áreas protegidas no extremo norte amapaense atinge fortemente a população que, sem maior apoio para a formalização de suas atividades, é obrigada a permanecer produzindo na 
ilegalidade. Depreende-se de Silva (2013) que a problemática da situação fundiária é um dos maiores entraves para o desenvolvimento local de Oiapoque.

Impossibilitados de acessar a titulação definitiva de suas áreas, empreendedores locais de diversos setores (pesca, movelaria e até o turismo) deixam de ter acesso a programas de fomento. Aspecto esse que freia a dinamização da economia local e impede a instalação de empreendimentos de maior porte, tais como indústrias.

Em situação econômica vulnerável, muitos moradores do município (amapaenses, paraenses, maranhenses e outros) optam por aventurar-se nos garimpos clandestinos da Guiana Francesa. De acordo com Nascimento e Tostes (2008), os movimentos pendulares de brasileiros para a Guiana Francesa e de guianenses para o Brasil datam da década de 1960. Para os autores, por parte dos brasileiros, tais movimentos são estimulados pela busca de emprego e pela esperança de uma renda melhor, uma vez que a moeda do outro lado da fronteira (o euro) é mais forte que a moeda brasileira. Já por parte dos guianenses, a motivação é a busca de diversão e mercadorias, cujos preços são favorecidos pelo cambio do lado brasileiro.

O movimento pendular do qual falam Nascimento e Tostes (2008) proporciona certa dinamização ao comércio de Oiapoque. Vindos do lado francês, os turistas atravessam o rio Oiapoque em pequenas embarcações denominadas localmente como catraias ${ }^{3}$ para comprar produtos e/ou divertir-se no lado brasileiro. Em geral, esse movimento ocorre com maior intensidade nos finais de semana e nos períodos em que o governo francês faz o pagamento de seus funcionários (SENA DOS SANTOS, 2009).

Aquecido por esse vai-e-vem pendular, atualmente, o comércio é um dos setores que mais movimenta a circulação de dinheiro no município de Oiapoque. Os empregos da administração pública também possuem participação importante. Contudo, até então, as oportunidades econômicas advindas desse aspecto peculiar da fronteira entre Oiapoque e Guiana Francesa não são suficientes para elevar os padrões da qualidade de vida local. Assim como na maioria dos municípios amapaenses, é grande o número de desempregados que sobrevivem de atividades econômicas informais e incertas.

\footnotetext{
${ }_{3}^{3}$ Pequenas embarcações de alumínio com motor de popa.
} 
Mais recentemente, Oiapoque vive expectativas de desenvolvimento local a partir do início do funcionamento da Ponte Binacional e das possíveis oportunidades advindas desse elo físico com o território francês. A ponte faz parte dos projetos geopolíticos de integração nacional com os países da Pan-Amazônia e do Mercosul. O início de sua utilização para a travessia de pessoas e mercadorias, bem como a total pavimentação da BR-156 (que liga Oiapoque até a capital Macapá), vislumbra interligar fisicamente o Brasil com a Guiana Francesa, Suriname e Guiana. Conforme Silva (2013), essa conexão física será permitida através da rodovia Transguianense (Figura 4).

Segundo o autor, a execução desse projeto permitirá: i) o aproveitamento do Porto de Santana/AP por outros países para fins de intercâmbio comercial; ii) a utilização da BR-156 para a fomentação do potencial turístico do estado do Amapá; iii) a minimização de problemas de infraestrutura e a consequente melhoria no trânsito de mercadorias e pessoas.
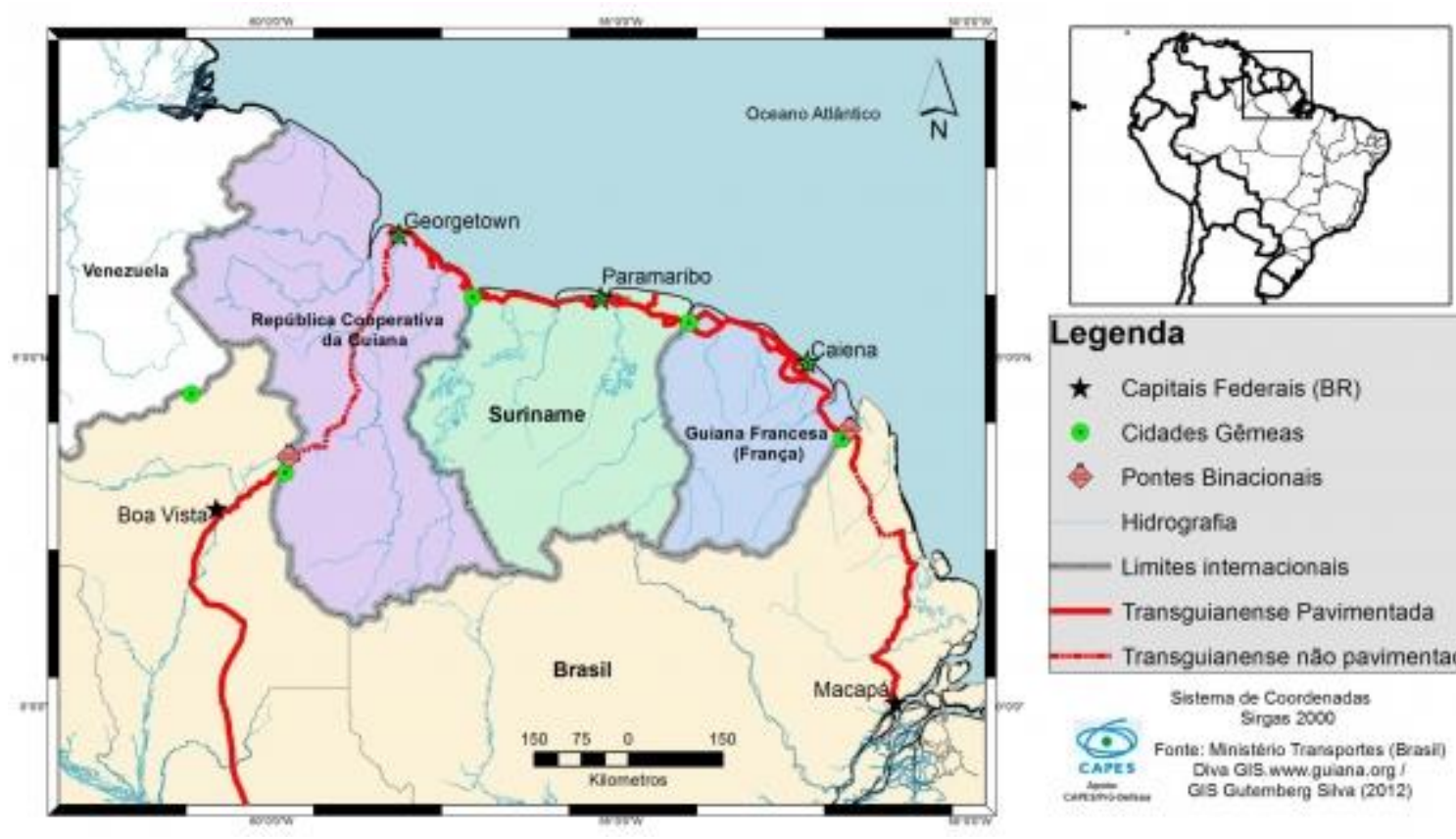

Figura 4: Rodovia Transguianense Fonte: Silva (2013)

Para Nascimento e Tostes (2008), a dinamização urbana de Oiapoque seria natural se a motivação para a execução de toda essa infraestrutura logística não tivesse uma dimensão transnacional e não fosse vinculada à IIRSA (Iniciativa para a Integração da Infraestrura da América do Sul. 
Os autores esclarecem que a IIRSA é um plano baseado em sete projetos setoriais e dez eixos de integração. Esses projetos objetivam integrar vários tipos de transporte (fluvial, marítimo, rodoviário e ferroviário) para conectar a América do Sul aos mercados internacionais de todo o planeta. A grande problemática visualizada por eles é que no plano de ação da IIRSA não se faz qualquer referência ao desenvolvimento urbano em escala local.

Dessa forma, depreende-se do pensamento de Nascimento e Tostes (2008) que, contrariando as expectativas atuais da população de Oiapoque, a cidade corre o risco de permanecer sendo um simples ponto de passagem para clandestinos e para o fluxo de mercadorias que poderão proporcionar o desenvolvimento em centros urbanos maiores, distantes do município.

Exposta a trajetória histórica, o contexto econômico e as expectativas para o futuro, torna-se evidente a necessidade de estratégias de desenvolvimento endógeno que capacitem a sociedade de Oiapoque e dote de criticidade e qualidade técnica seus atores sociais para que estes saiam das margens e tornem-se protagonistas de sua própria história. Logo, é essa necessidade que justifica a importância social da presença da Universidade Federal do Amapá no município, de seus cursos de graduação e do curso de Licenciatura em História, objeto de atenção desse texto.

\section{Que ensino de História queremos?}

Para Selva Guimarães Fonseca (2004, p.43), um dos caminhos para repensar o ensino de História no Brasil consiste em buscar renovar, cotidianamente, nossas práticas dentro e fora das instituições de ensino. Torna-se indispensável, nesse sentido, admitir que não cabe mais um ensino de História ancorado na leitura e memorização de narrativas históricas atreladas a uma determinada vertente historiográfica ou a um determinado posicionamento ideológico.

Essa prática reforça situações de aprendizagem em que a autoridade do especialista, no âmbito do ensino superior, ou do livro didático, no âmbito da educação básica, não é passível de ressignificação, reformulação ou questionamento. As interpretações sobre o passado derivam das circunstâncias 
históricas de quem as produziram bem como das condições de produção do discurso, no interior das quais se consideram o lugar institucional ocupado pelo autor e as correntes de pensamento com as quais mantém certa afinidade, afinal, a construção do passado resulta de preocupações ou indagações atinentes ao momento da escrita.

Diante disso, defendemos que o aluno não se torna um cidadão crítico, autônomo e criativo, como almejam as Diretrizes Curriculares Nacionais para o Ensino Superior, apenas reproduzindo versões sobre o passado elaboradas por determinadas correntes historiográficas. Nesse sentido, julgamos oportuno que as disciplinas estejam ancoradas em diálogos intertextuais em que os graduandos tenham a liberdade de se posicionar, tendo em vista o caráter flexível e criativo do processo de construção do conhecimento histórico. Sob essa perspectiva, é mister que o docente desenvolva situações de aprendizagem que tornem os graduandos protagonistas de seu próprio processo de aprendizagem a fim de que oportunizem essa experiência de construção e/ou reconstrução com a comunidade em geral.

Esse é o grande desafio, a nosso ver, do curso de Licenciatura em História de Oiapoque.

Opomo-nos, nesse sentido, ao que muitos estudiosos chamam de 'ensino instrucionista' em que o professor transmite um conteúdo, que ele copiou de alguma obra de sua preferência, para um aluno que também vai copiar a fim de que, mais tarde, este conteúdo seja novamente transcrito em avaliações.

Defendemos que é desaconselhável ao docente 'copiar', ou seja, 'reproduzir' apenas o pensamento alheio, porquanto o docente deve ministrar suas aulas a partir daquilo que ele produz, de tal forma que, se o professor não produz conhecimento próprio, não tem o que ensinar para o aluno.

A contratação de $100 \%$ dos docentes no regime de dedicação exclusiva contribui para que o docente não só se familiarize com as necessidades educacionais e desenvolva projetos de intervenção para satisfazê-las, mas também com as experiências cotidianas vivenciadas pelos estudantes, a qual atua como pano de fundo para as reflexões historiográficas em temas abordados na sala de aula.

Por se tratar de uma região carente de políticas públicas voltadas à educação e à assistência social, as atividades de extensão desenvolvidas pelo Colegiado de 
História do campus Binacional/Oiapoque, tais como palestras, minicursos e pesquisas de campo objetivam finalidades práticas: conscientizar a comunidade acerca de seu potencial transformador, especialmente, no que diz respeito ao acesso à educação de qualidade, aos órgãos públicos que asseguram direitos à população bem como questões atinentes à construção de identidades religiosas e suas fronteiras sociais, criminalidade, relações de gênero e suas implicações político-culturais, entre outros temas.

Para nos desvencilharmos da concepção de 'ensino instrucionista' em História, recomendamos, entre outras possibilidades, é claro, que o estudo de um acontecimento histórico esteja ancorado na leitura de fontes históricas e de, pelo menos, duas abordagens historiográficas divergentes.

É importante que o graduando perceba que cada fonte histórica exprime uma versão sobre o passado, isto é, ela perfaz uma forma de mediação do passado, a partir da qual outras mediações possíveis serão construídas. Fica claro que a construção do conhecimento histórico é uma atividade linguística e intertextual elaborada a partir de mediações de diferentes autores sobre o passado, os quais filtram os acontecimentos históricos vivenciados ou pesquisados sob perspectivas particulares. Procura-se conscientizar os alunos acerca dessa prática de ensino desde o primeiro semestre.

Isso quer dizer que os registros históricos não produzem 'verdades' sobre o passado a que fazem referência; são em geral pontos de vista sobre o passado que certamente nos ajudam a compreendê-lo. Enfim, nosso desafio, como professores de história, independentemente do nível de ensino em que atuamos, consiste em mostrar que a história não é um discurso pronto e acabado, mas um conhecimento, assim como os demais, em constante processo de construção, reformulação ou ressignificação.

Permitir ao aluno construir seus próprios conhecimentos históricos a partir do uso de fontes históricas, de diferentes abordagens historiográficas e a partir de suas experiências cotidianas é um exercício que não desperdiça a potencialidade criativa dos jovens e sua capacidade de propor hipóteses.

Parafraseando Paulo Freire acerca da crítica que tece sobre o que chama de 'educação bancária', trata-se de uma concepção de ensino que concebe o docente não como profissional que tudo sabe ou aquele que profere 'verdades' ou respostas 
certas a serem memorizadas pelos alunos como critério de aprovação na disciplina; ao contrário, o docente passa a ser aquele que contribui para o processo de construção de conhecimentos. Entendemos que o conhecimento histórico, como todo conhecimento, é provisório, é constantemente refeito, mas observamos que esse entendimento demora a chegar à sala de aula, por quê?

Uma hipótese talvez esteja relacionada ao ensino de História em muitas universidades brasileiras que infelizmente não perdeu o caráter instrucionista ou conteudista e meramente descritivo em que o docente transfere informações a serem internalizadas pelos alunos.

Outra hipótese, que pode estar associada à primeira, relaciona-se ao uso do livro didático como ferramenta única de consulta pelo professor. Isso faz com que o professor apenas reproduza uma versão da história, que é imposta aos alunos, em geral, acriticamente. Essa prática de ensino possivelmente se perpetua em razão das próprias condições de trabalho dos docentes na educação básica: excessiva carga horária de trabalho, insuficiente número de aulas de história por semana, ausência de investimentos públicos na formação continuada de professores, entre outros motivos.

Há também outro fator, a nosso ver, preocupante: estamos acostumados a políticas públicas centralizadas e verticais, de tal forma que os conteúdos e os currículos já desabam prontos, acabados aos professores de educação básica.

Esses 'pacotes educacionais', ainda que sustentem princípios como flexibilização, cidadania e autonomia, ao contrário do pregam, levam o professor a seguir os conteúdos previamente estabelecidos sob o pretexto de preparar o aluno para o mercado de trabalho e para a cidadania. Reflitamos, ainda que brevemente, sobre o que significa "preparar o aluno para o mercado de trabalho e para a cidadania".

Em primeiro lugar, não há consenso quanto a isso, nem um sentido unívoco. Há muitos significados, pois há diferentes concepções de cidadania e suas relações ou não com o mercado de trabalho.

Podemos, nesse sentido, perguntar-nos se isso significaria o adestramento de mão-de-obra para o mercado de trabalho em que o termo cidadania apenas perpetua desigualdades sociais na medida em que solicita a aceitação da ordem social vigente, no interior da qual os 'direitos' geralmente são entendidos como dádivas ou presente dos governos municipais, estaduais ou federais? Enfim, o que 
se entende por formação para o mercado de trabalho e para o exercício da cidadania?

Pelo menos sabemos que o exercício da cidadania não ocorre por meio de práticas de ensino assentadas na memorização e na repetição, reminiscências do ensino jesuítico na educação brasileira, que teve sua importância em determinado momento histórico.

A proposta curricular de História do estado Amapá traz consigo uma lista de conteúdos a serem ministrados em cada etapa escolar, os quais não dialogam com as experiências cotidianas e temas que preocupam os jovens. Isso leva muitos docentes a abordar os conteúdos a despeito das inquietações ou predileções dos estudantes.

Por exemplo, a memorização das fases políticas do Egito Antigo e das principais realizações dos faraós serve para que? Em que medida a exposição da história econômica da Grécia Antiga torna o cidadão mais crítico e participativo ou contribui para a autonomia dos alunos no processo de construção de conhecimentos escolares? É essa a narrativa que encontramos nos livros didáticos e que atende às exigências das diversas propostas curriculares estaduais, não é? Não que tais informações não sejam relevantes para as sociedades antigas em questão, questionamo-nos apenas o fato de este não ser o fim último das situações de aprendizagem.

De todo modo, temos aqui no mínimo a existência de dois mundos: o mundo do professor, que pretende abordar os conteúdos escolares prescritos pela proposta curricular e o mundo dos alunos repleto de dúvidas, inquietações, angústias, descobertas, prazeres, etc. Estes mundos geralmente não dialogam, porque estão encastelados em seus próprios interesses e objetivos.

Então, reforçamos a importância do contato dos alunos com diferentes tipos de fontes históricas (imagens, mapas, documentos escritos, artefatos arqueológicos, documentários) e as diferentes leituras que foram produzidas sobre elas bem como uma reflexão de como tais leituras foram produzidas, ou seja, a partir de quais circunstâncias históricas e quais condições de produção. Defendemos que essa prática de ensino contribui para que o estudante, diante de um discurso político, por exemplo, considere a intencionalidade da construção, organização e seleção das 
ideias, tendo em vista quem o produziu, o público para quem se dirige e a própria arquitetura do texto.

Se o educando receber o conhecimento pronto e acabado não poderá compreender as particularidades da produção daquele tipo de conhecimento e consequentemente sua importância social. Além disso, é preciso lembrar que o conhecimento representa a expressão do mundo em que se vive ou se deseja viver, ou seja, sua razão de existir está impregnada de valor e de importância para aquele que o construiu.

Neste ponto, concordamos com Pedro Demo (1990) para quem o processo de aprendizagem deve ter um caráter investigativo, ou seja, deve estar centrado na pesquisa, na investigação, na proposição de hipóteses ou solução de situaçõesproblema.

O conhecimento dado, pronto e acabado é autoritário, catequético, doutrinário; o conhecimento construído é democrático, cético, crítico. A questão já denunciada por diversas gerações de pedagogos consiste na importância de aproximar os conteúdos escolares das experiências cotidianas de nossos alunos a fim de que o ensino superior e, por extensão, a educação básica promova uma reflexão não só sobre a vida em sociedade, mas também sobre o papel que desempenhamos dentro dela. Se assim o fizermos, a abordagem de conteúdos históricos será indispensável à orientação para 'vida', como sustenta Jörn Rüsen, o que implica a racionalização e desnaturalização de nossas próprias experiências cotidianas.

\section{Considerações finais}

O conhecimento histórico contribui para encarar o mundo em que vivemos com uma postura crítica e reflexiva ao desnaturalizar as experiências humanas através do tempo. Isso implica reconhecer que a forma como pensamos e a forma como agimos, ou melhor, nossas concepções de certo ou errado, lícito ou ilícito, válido ou inválido são construções humanas que derivam de práticas culturais produzidas pelo homem em determinado momento histórico.

Desejamos, através da formação de professores de História, fomentar o verdadeiro potencial transformador dessa área do conhecimento científico: a prática da 
"inclusão histórica". Ao perceber que a História é construída por gente comum, o aluno, graduando e futuro professor, se sentirá próximo, qualificado e inclinado a exercê-la.

A irradiação desse movimento poderá despertar o sentimento de pertencimento ao município. Esse sentimento, em nossa avaliação, abrirá caminhos para o desenvolvimento endógeno e permitirá que pessoas comuns exijam, por ter direito de participação, opinião e decisão, alterando, dessa forma, seu status quo de meros expectadores para sujeitos críticos e transformadores de seu meio.

\section{Referências}

BRASIL. Secretaria de Educação Fundamental. Parâmetros Curriculares Nacionais. Brasília: MEC/SEF, 1998.

- Secretaria de Educação Fundamental. Parâmetros Curriculares Nacionais: História. Brasília: MEC/SEF, 1998.

- MEC. CNE. Diretrizes Curriculares Nacionais Gerais para a Educação Básica - Parecer 7/2010: Diário Oficial da União, 9 jul. 2010, seção 1.

CANEN, A. Educação multicultural, identidade nacional e pluralidade cultural: tensões e implicações curriculares. Cadernos de Pesquisa. n. 111, 2000.

GRANGER, S. O Contestado Franco-Brasileiro: desafios e consequências de um conflito esquecido entre a França e o Brasil na Amazônia, Revista Cantareira. Ed. 17/Jul-Dez, 2012.

LAVILLE, C. A guerra das narrativas: debates e ilusões em torno do ensino de História, Revista Brasileira de História. SP, v.19, n. 38, p. 125-138, 1999.

NASCIMENTO, O. A. do; TOSTES, J. A. Oiapoque - "Aqui começa o Brasil": as perspectivas de desenvolvimento a partir da BR-1 e da Ponte Binacional entre o Amapá e a Guiana Francesa. In: Anais IV Encontro da Associação Nacional de Pesquisa e Pós-Graduação em Ambiente e Sociedade, Brasília-DF, 2008.

SENA P. G. dos S., Territorialidades e espaços públicos em pequenas cidades da Amazônia: o caso de Oiapoque-Amapá. Monografia de Conclusão de Curso, Universidade Federal do Amapá, 2009. 
SILVA, G. de V. Desenvolvimento econômico em cidades da fronteira amazônica: ações, escalas e recursos para Oiapoque-AP. Confins, 17, 2013, disponível em: http://confins.revues.org/8250 ; DOI : 10.4000/confins.8250

VIDAL, L. B. Povos indígenas do baixo Oiapoque: o encontro das águas, o encruzo dos saberes e a arte de viver. Museu do Índio. IEPÉ: 2007.

PENNAFORT, H. Estórias do Amapá. Macapá: Imprensa Oficial, 1984.

RÜSEN, J. Didática - funções do saber histórico. In: História Viva: teoria da História, formas e funções do conhecimento histórico. Trad. Estevan de Rezende Martins.Brasília: Editora universidade de Brasília, 2007. Aprovado em 14 de setembro de 2016. 